Ann. Abeille, I965, 8 (4), 321-323.

\title{
L'ACTION DE LA VIROSE A NOYAUX DENSES SUR IES LARVES DE GALLERIA MELLONELLA DANS LES RUCHES
}

\author{
P. LAVIL, I. FRESAAYE et C. VAGO \\ Station expinimontale d'Apiculture, Centre de Recherches agronomiques du Sud-Est, \\ Montfaret (Vaucluse) \\ et Laboratoive de ('ytopathologie, Saint-Christol (Gart)
}

SOMMAIRE

L'élimination ou la diminution des populations du Lépidoptère Galleria mellonella ont été observées aprés traitement au virus des noyaux denses de ruches peuplées ou non d'abeilles.

Récemment un nouveau type de maladie à virus a été mis en évidence chez le Lépidoptère Galleria mellonella (VAgo, Meynadier, Duthoit, ig64; MeynaDiER, VAGo, Plantevin, Atger, I964). Les virus isolés sont parasphériques de 20 à 23 mu. Les lésions sont nucléaires et consistent en l'accumulation de ces éléments sous forme de corps d'inclusion intranucléaires (Amargier, Vago, MeynadirR, r965). Aussi bien après injection qu'après contamination buccale, l'évolution de la virose, extrêmement rapide, se détoule en 5-6 jours. La pathogenèse a été suivie également in vitro sur cultures cellulaires de Lépidoptères (VAGO, LuCIANI, Ig65).

Ces recherches ayant mis en évidence un effet pathogène particulièrement rapide et une contagiosité rarement vue chez une maladie d'invertébrés, nous avons envisagé de rechercher l'action qu'exerce ce virus dans le milieu naturel de G. mellonella dans les ruches d'abeilles peuplées ou non. En effet, on sait qu'en apiculture les larves de $G$. mellonella constituent un ennemi dont la nocivité dépend de l'importance et de la vigueur des colonies, ainsi que des conditions d'alimentation et climatique. De même pour la conservation des rayons de cire hors de la saison apicole, cette espèce représente un danger potentiel pouvant apparaître à la moindre insuffisance de soin. 
De ce fait, il était intéressant, en plus des recherches sur le comportement du virus dans le milieu naturel de son hôte d'obtenir aussi des renseignements pouvant avoir des conséquences économiques pour l'apiculture.

Les recherches effectuées ont consisté en l'examen des suites des contaminations de ruches par le broyat frais ou congelé de larves de Galleria fortement atteintes de la virose. Cette matière infectieuse a été introduite dans les ruches, soit par badigeonnage rapide des rayons, soit par pulvérisation. Les infections ont eu lieu parallèlement dans des ruches contenant seulement des rayons et dans celles peuplées d'abeilles.

Dans les ruches contenant des rayons sans peuplement d'abeilles, deux types se produisent naturellement.

Le premier présente une population dense de Galleria amenant l'élévation rapide de la température à $28-30^{\circ} \mathrm{C}$, au milieu des larves. Une forte mortalité apparaît 9 à Io jours après la contamination. Le tissage de galeries est visiblement faible. Les symptômes de la maladie sont identiques à ceux décrits par MEYYADIER, VAGo, Plantevin, Atrer. (I964). La nymphose a quelquefois eu lieu, mais les papillons sont anormaux et ont des difficultés de vol.

Dans le deuxième type ne présentant qu'un début d'attaque de Galleria et ayant une température interne de $20^{\circ} \mathrm{C}$ environ, on constate, 20 jours après la contamination, une mortalité partielle surtout caractérisée par sa localisation. En effet, par endroits, une forte mortalité de larves de toutes tailles est observée alors qu'en d'autres points de la ruche, la maladie est peu avancée.

Dans les ruches peuplées de colonies faibles en abeilles, la mise en évidence de larves malades ou mortes a posé de grandes difficultés car les abeilles assurent un nettoyage régulier des rayons et éliminent les Galleria mortes ou malades, ou couvrent de propolis les parties qu'elles ne peuvent pas détacher. Dans ces cas, la disparition rapide des Galleria dans les ruches contaminées de virus par rapport à leur diminution progressive et incomplète dans les ruches non traitées a dénoté l'action virale.

L'ensemble de ces observations montre l'existence d'une action pathogène du virus des noyaux denses vis-à-vis de $G$. mellonella dans les ruches. Cette action est remarquable lorsque la population des larves est forte, car la température étant plus élevée, la pathogenèse est rapide et l'activité accrue des larves aide la contamination. Bien qu'il soit difficile de définir l'action de virus dans une ruche peuplée d'abeilles, l'effet favorisant du virus sur la destruction de Galleria est nettement apparu.

D'une manière générale, le développement de la maladie dépend des facilités de contamination au nombre de foyers de Galleria et, dans les ruches peuplées, à l'activité des abeilles.

Ces résultats permettent enfin d'envisager des applications pratiques de ce virus en lutte biologique contre $G$. mellonella, notamment dans les ruches faiblement peuplées et pendant le stockage des rayons. 


\section{SUMMARY}

Action of the virus of dense nuclei upon the larves of Galleria mellonella in bee-hives.

Total or partial control of the population of Galleria mellonella (Lepidoptera) have been observed after treatment of bee-hives, with or without bee population by the Virus of Dense Nuclei.

\section{RÉFÉRENCES BIBLIOGRAPHIQUES}

Amargier A., Vago C.. Mexpadier (i., 1965. Étude histopathologique d'un nouveau type de virose mis en évidence chez le Lépidoptère Galleria mellonella. Arch. Ges. Virusforsch., 15, 659-667.

Meynadier G., Vago C., Plantevin G., Atger P., ig64. Virose d'un type inhabituel chez le Lépidoptère Galleria mellonella I. Rev. Zool. Agric. et Appl., 63, 207-208.

Vago C., Luciani J., 1965. Développement du virus de la maladie des noyaux denses de Galleria mellonella en culture de tissus de Lépidoptères. Experientia, 21, 393.

Vago C., Meynadier G., Dutirom J. L., ig6. F́tude d'un nouveau type de maladie à virus chez les Lépidoptères. Ann. Epiphyties, 15, $475-479$. 